\title{
Dual Radiator Based Low Profile Fan Beam Antenna for Millimeter Wave Fencing System
}

\author{
Pramendra Kumar Verma ${ }^{1 *}$, Raj Kumar ${ }^{1}$, V. K.Singh ${ }^{1}$, Ashok Kumar ${ }^{1}$ \\ ${ }^{1}$ Defence Electronics Application Laboratory, Dehradun, India \\ *Corresponding author: pramendra@deal.drdo.in
}

\begin{abstract}
The paper describes the design, development, and characterization of a low profile, lightweight and linearly polarized fan beam radiating array antenna for millimeter wave fencing system. Dual antenna topology has been proposed for each transmit and receive tower to obtain maximum coverage area compared to a single antenna configuration. The radiator placement (height) has been optimized to minimize the dead zone region. Proposed RF fencing system utilizes an 8x32 probe-fed microstrip patch array antenna developed on 10 mils RT Duroid dielectric substrate material. ANSYS's High-Frequency Structure Simulator (HFSS) full-wave EM software has been utilized for simulation and analysis of designed radiating array. VSWR of the realized antenna is $1.75: 1$ over the frequency band of $34.5 \mathrm{GHz}$ to 35.5 GHz. The E-plane and H-plane HPBW of the developed antenna at $35 \mathrm{GHz}$ is 8.4 and 2.2 degrees respectively. The measured gain of the antenna is better than $25.4 \mathrm{dBi}$ over the frequency band $34.5 \mathrm{GHz}$ to $35.5 \mathrm{GHz}$.
\end{abstract}

Keywords: Array Antenna, Dual Topology, Fan Beam, millimeter wave fencing

\section{Introduction}

The radio frequency fencing systems are required to monitor and protect the open or unmonitored boundaries of the countries or critical infrastructures such as airports, prestigious properties, power grids, and public buildings from unwanted intruders. The traditional method of border security is to have wire fencing at the border but it has several limitations like not possible to cover all the sites, difficult to monitor, damaging by intruders, etc. For better monitoring, continuous patrolling is also required at the border. There are several other methods for intruder detection and security such as laser \& radar, IR security system, fiber optic intrusion detection system, leaky cable detection, microphonic sensors measuring acoustic signals, radar, and on-site cameras, smart fence using geophones and microphones, etc. [1-6].

Millimeter wave (mmWave) detection system not only enhances the security system but also provides an allweather protection system, which can operate in adverse weather conditions like fog, haze, smoke, etc. This system uses MM wave radiated beam from antennas to establish a protection zone as RF (radio frequency) fencing [7-8].

RF fencing can be implemented in two ways namely the monostatic system or bistatic system. The monostatic detection system uses a trans-receiver which transmits the $\mathrm{RF}$ signal and receives the same by reflection from some object. In the case of the moving object, this system produces the Doppler shift in frequency. This Doppler shift in frequency triggers the alarm system based on its threshold value. A monostatic detection system requires a large number of corner reflector to produce the detection zone and alignment of these corner reflectors with antenna is critical. Due to misalignment, sometimes a certain number of false alarms are possible in this type of system.

Bistatic fencing system uses transmitting and receiving system at opposite ends and the detection zone is created in between them by the radiated beam from the transmitting antenna. The height of the transmitting and receiving antenna depends on the volumetric size of the detection zone. The change in power level at the receiver due to the intrusion of an object triggers the alarm. The performance of this type of system depends on operating frequency, radiation characteristics, and the height at which the antenna is placed. It is also not easy to jam this system because it creates an alarm whenever the power level changed.

To cover a complete border area large numbers of RF fencing systems will be required, hence the system should have low cost, lightweight, easy to install, highly reliable and should be able to provide the real-time detection of any intrusion. Many types of RF fencing systems are commercially available such as Microwave Open Space Detection of Microguard ${ }^{\mathrm{TM}}$, Microwave fencing system of Fiber SenSys perimeter security USA, PREDIX-200- The microwave barrier product of Umires Europe, Microwave Bistatic Sensor of Forteza Russia. All of them are at L, X or $\mathrm{K}$ band and also they utilize single antenna topology.

Design of antenna at higher frequency band is more challenging compared to lower frequency band but the size and weight of antenna system is significantly reduced. At Ka-band frequency, the radiated beam is highly directive as compared to the lower frequency band of operation for the same size of the antenna. Also, Fan beam antenna with a wider elevation radiation pattern and a narrower azimuth radiation pattern provides a wider beam coverage area. In a single radiator based system, the dead zone near to mast can be minimized by reducing the height of the antenna, resulting in the reduction in effective volumetric area. Dual radiator- based systems produce the larger volumetric area of protection and minimum dead zone compared to a single radiator in RF fencing system and also produce the false alarm due to nearby moving objects. Circular or Linear polarization both can be used for this application. It is easy to generate the linearly polarized wave compare to circularly polarized wave at millimeter wave frequency. 
Since millimeter wave detection system is based on perturbation in common volume area hence linear polarized wave is preferred. In the present work, the dual radiator approach has been used to realize a dead zone free millimeter wave fencing system at Ka-Band frequency. Figure 1 shows the RF fencing system using dual radiator topology.

Millimeter wave fencing system uses two transmitting and two receiving antenna on each mast at heights $h 1$ and $h 2$ respectively. Both transmit antennas are aligned with their respective receive antennas. The height of lower transmit and receive antenna has been optimized in such a manner that no one could cross the area even in crawling conditions. This configuration reduces the dead zone formed just beneath transmit and receive antenna number 2. Two antenna systems produce the larger volumetric area of protection as compared to a single antenna in the RF fencing system. The radiated beam from two antenna systems along with the dead zone is shown in Figure 2.

\section{Design methodology and simulation}

To meet the requirement of a low profile, lightweight, and low-cost radiating system, out of several available antenna configurations, a microstrip based patch array antenna has been selected in the present work. Other configurations have many limitations like pillbox has a large volume and weight [9] and the slotted array has severe fabrication criticality. Microstrip array antenna possesses several techniques to enhance its bandwidth like using thick substrate material, stacking techniques, creating a slot in the radiating element, etc.

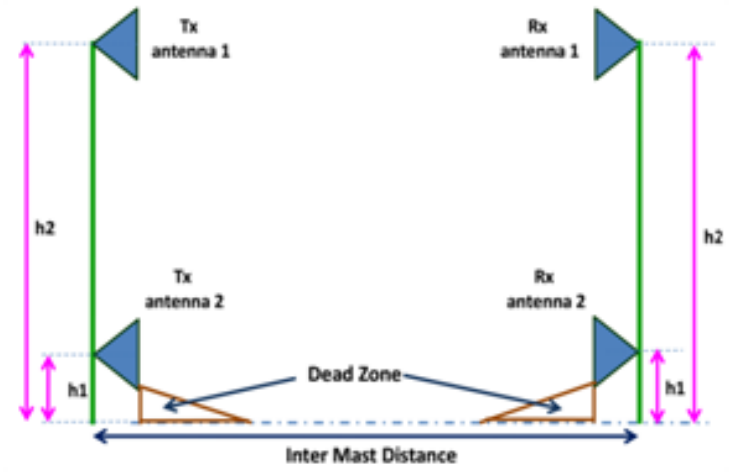

Fig.1. Dual Antenna Topology for MM Wave fencing System.

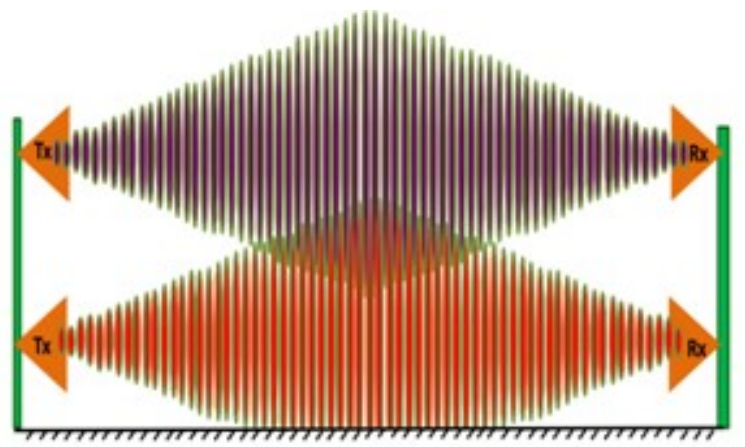

Fig. 2. RF field distribution between antennas for RF fencing system.
The beam width of the RF fencing antenna is decided by the range requirement and radiated beam characteristics (height and width) at the middle point of transmitting and receiving system. For 300 meters distance between transmit and receive tower, the required beam width of antenna for vertical $(\mathrm{E})$ plane and horizontal $(\mathrm{H})$ plane has been calculated as 8.4 degrees and 2.2 degrees respectively. The vertical beamwidth of the upper antenna decides the height of the detection zone and horizontal beamwidth decides the width of the detection zone. The height of the lower antenna on the mast decides the area of the dead zone, hence to minimize the dead zone the height (h1) should be as minimum as possible. For the present case, the range of fencing system has been considered as 300 meter and upper antenna height as 1 meter. The calculated area of dead zones is shown in Table 1. For lower antenna height as 0.2 meters, the dead zone becomes a right angle triangle whose height and base are 0.2 meters and 2.76 meters respectively. This dead zone height is so small that intruder cannot bypass the system without detection even in crawling condition.

The calculated volumetric area for lower antenna height (0.2 meters) and upper antenna height (1.0 meters) are shown in Table 2 for different ranges. It was observed that for the same height of upper and lower antenna volumetric area increases as the distance between transmit and receive tower increases. The operating range of the $\mathrm{mm}$-wave fencing system depends on operating frequency, transmitted power, gain of transmitting and receiving antenna, path loss, receiver sensitivity, etc.

To meet the required beamwidth of the antenna for RF fencing system, an 8x32-microstrip patch array antenna has been designed, simulated, optimized, and developed. The selection of proper dielectric material at mmWave frequency allows maximizing the radiation efficiency of the antenna as well as minimizing the generation of the surface wave on dielectric material [10-14]. Substrate height (h) of the antenna array should meet the following condition to minimize the surface wave loss [15:

Table 1: Dead zone area for the various height of the lower antenna

\begin{tabular}{|c|c|c|}
\hline $\begin{array}{l}\text { Lower Antenna } \\
\text { height h1 } \\
\text { (Meters) }\end{array}$ & $\begin{array}{l}\text { Base of } \\
\text { Dead } \\
\text { Zone } \\
\text { (Meters) }\end{array}$ & $\begin{array}{l}\text { Dead Zone Triangle Area } \\
\text { (Height, Base) }\end{array}$ \\
\hline 0.1 & 1.38 & 0.1 meters, 1.38 meters \\
\hline 0.2 & 2.76 & 0.2 meters , 2.76 meters \\
\hline 0.3 & 4.14 & 0.3 meters , 4.14 meters \\
\hline 0.4 & 5.52 & 0.4 meters , 5.52 meters \\
\hline 0.5 & 6.91 & 0.5 meters , 6.91 meters \\
\hline
\end{tabular}

Table 2: Detection area for the various ranges

\begin{tabular}{|c|c|c|}
\hline $\begin{array}{c}\text { Range } \\
\text { (meters) }\end{array}$ & $\begin{array}{c}\text { Detection Width } \\
\text { (meters) }\end{array}$ & $\begin{array}{c}\text { Detection length } \\
\text { (meters) }\end{array}$ \\
\hline 100 & 1.74 & 4.62 \\
\hline 200 & 3.49 & 7.23 \\
\hline 300 & 5.22 & 11.86 \\
\hline 400 & 6.98 & 15.47 \\
\hline
\end{tabular}




$$
\frac{h}{\lambda_{0}} \leq \frac{0.3}{2 \pi \sqrt{\varepsilon_{r}}}
$$

(where $\lambda_{0}$ is operating wavelength and $\mathrm{c}$ is the velocity of light.)

Considering all of the above design aspects, a 10mil RT Duroid 5880 substrate material $\left(\varepsilon_{\mathrm{r}}=2.22, \tan \delta=0.0009\right)$ with copper cladding thickness of 17 microns has been selected for the design of radiating element. To obtain equal beam width in both $\mathrm{E}$ and $\mathrm{H}$ plane a square patch has been considered with $2.5 \mathrm{~mm}$ side. The gain of a single square patch antenna is 6.0 $\mathrm{dBi}$. Based on the required gain and beam width, $8 \times 32$ patch array has been finalized and the corporate feed method is used to feed the array antenna.

To feed the array antenna, phase and amplitude matched power divider network is used. The edge impedance of the square patch is $200 \mathrm{ohms}$, hence to match the antenna with transmission line a quarter-wave transformer with $143 \mathrm{ohms}$ is used. Initially, $1 \times 2$ patch array antenna designed with feeding line than $2 \times 2$ patch array. The HFSS model of $2 \times 2 \& 8 \times 32$ Patch array antenna with the feed network is shown in Figure 3. The CAD model of the antenna with mast is shown in Figure 4.

Modeling, simulation, and optimization of the patch array antenna have been carried out using full wave ANSYS's HFSS EM simulation software tool. To cater to the loading effect of the antenna feeding network, the antenna system has been properly optimized over the frequency band of 34 to 36 $\mathrm{GHz}$ at each stage of array elements.

The optimized dimension of the patch element at $35 \mathrm{GHz}$ is $2.5 \mathrm{~mm} \times 2.5 \mathrm{~mm}$ and the width of $143 \mathrm{ohms}, 100 \mathrm{ohms}, 70.7$ ohms are 90 microns, 230 microns, 400 microns respectively. Tolerance analysis of the antenna system was carried out before realizing it. The simulated radiation pattern of $8 \times 8$ and $8 \times 16$ array antenna are shown in Figure 5.

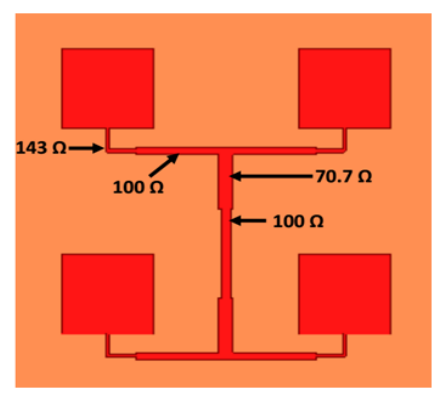

(a)

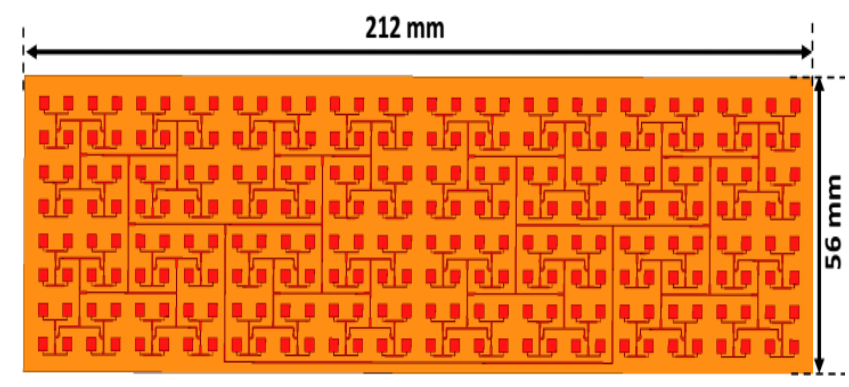

(b)

Fig.3. CAD model of (a) $2 \times 2$ (b) $8 \times 32$ Patch Array Antenna.

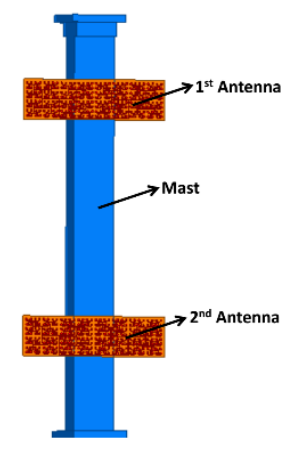

Fig.4. CAD model of Antenna placement on the mast.

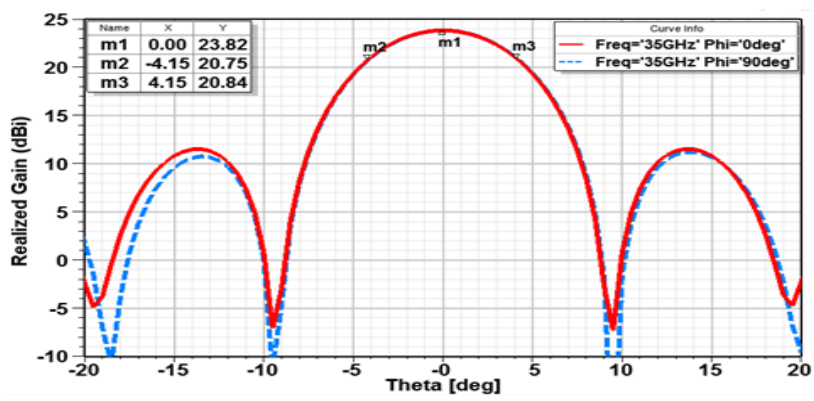

(a)

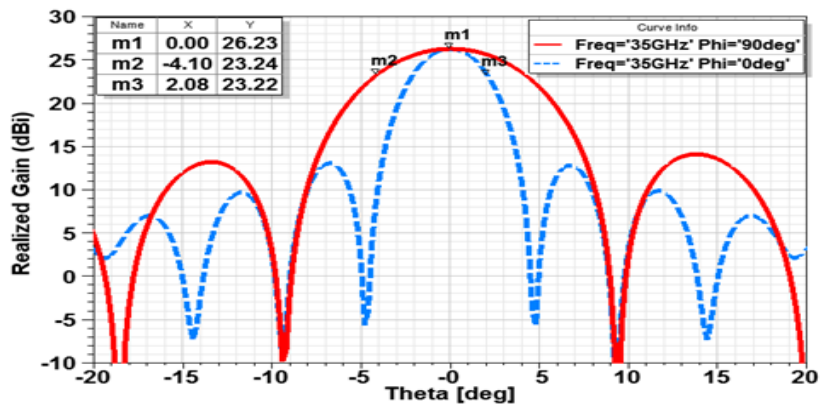

(b)

Fig.5. Simulated radiation pattern of Array antenna (a) $8 \times 8$ (b) $8 \times 16$.

After optimizing the $8 \times 16$ array antenna, the complete array of patch antenna i.e. 8 x32 has been modeled, simulated, and optimized over the desired frequency band. The simulated radiation pattern of $8 \times 32$ patch array antenna for both $\mathrm{E}$ and $\mathrm{H}$ plane (phi $=0$ and 90 degrees) at $34.5 \mathrm{GHz}, 35 \mathrm{GHz}$, and $35.5 \mathrm{GHz}$ frequencies are shown in Figure 6. The simulated radiation efficiency of antenna is shown in Figure7. Maximum simulated gain is achieved at $35 \mathrm{GHz}$ which is $27.89 \mathrm{dBi}$ while it is $27.06 \mathrm{dBi}$ at $34.5 \mathrm{GHz}$ and $27.32 \mathrm{dBi}$ at $35.5 \mathrm{GHz}$.

It was observed during simulation that by doubling the number of the element from $8 \times 8$ to $8 \times 16$, gain increases by $2.4 \mathrm{~dB}$, and further doubling the array element to $8 \times 32$ the gain increases only by $1.7 \mathrm{~dB}$. This occurs due to an increase in feeding losses of an $8 \times 32$ array as compared to $8 \times 16$ array antenna. The simulated half-power beamwidth of $8 \times 32$ array antenna at $35 \mathrm{GHz}$ is 2.08 degree (H-plane) and 8.4degree (Eplane) respectively. The optimized dimensions of the antenna are shown in Table 3 . The simulated radiation efficiency of the antenna lies between 73 to $80 \%$ over the frequency band of $34.5 \mathrm{GHz}$ to $35.5 \mathrm{GHz}$. 


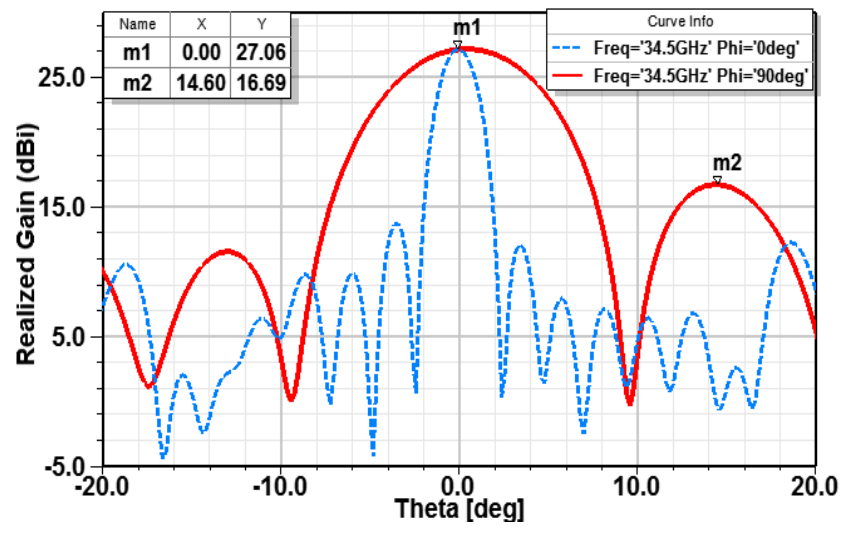

(a)

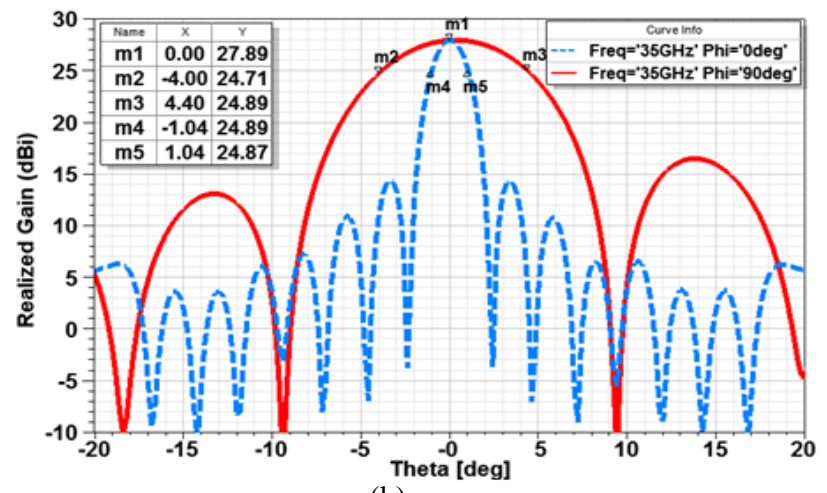

(b)

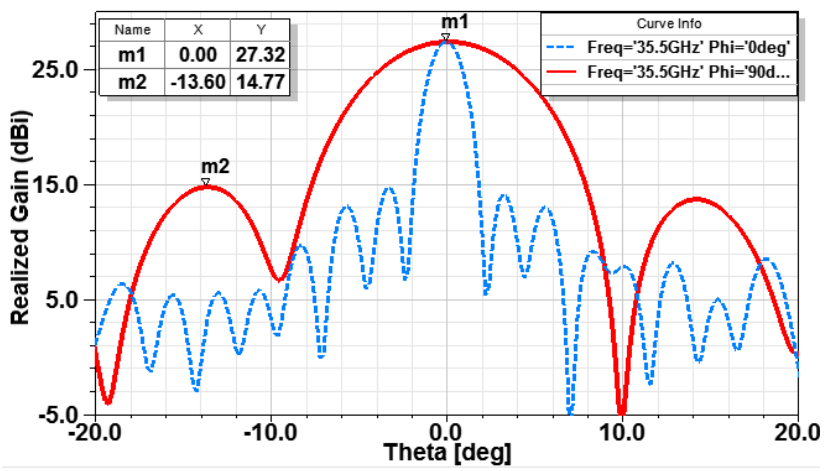

(c)

Fig.6. Simulated radiation pattern of $8 \times 32$ at (a) $34.5 \mathrm{GHz}$ (b) 35 $\mathrm{GHz}$ (c) $34.5 \mathrm{GHz}$.

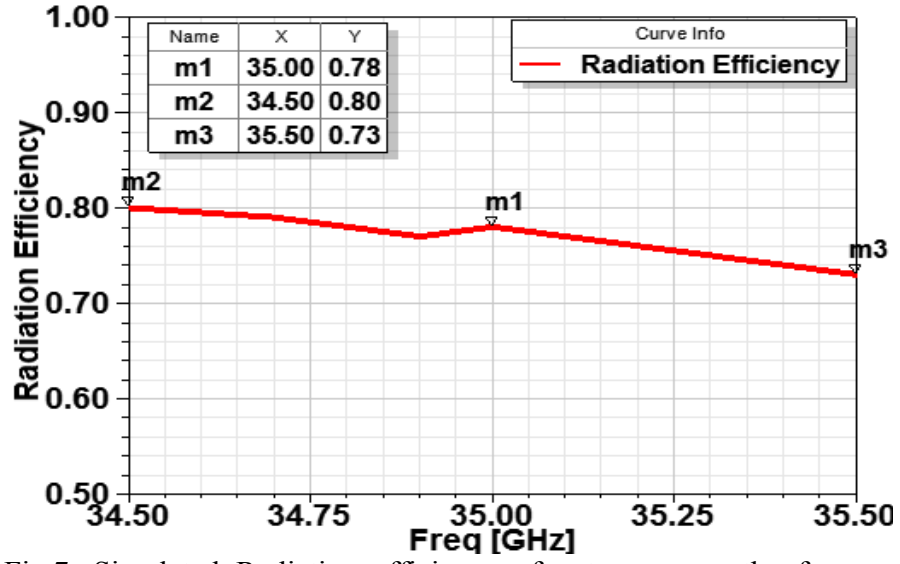

Fig.7. Simulated Radiation efficiency of antenna over the freq. band.
Table 3: Optimized dimensions of $8 \times 32$ array antenna

\begin{tabular}{|l|l|}
\hline Parameters & Values \\
\hline Thickness Dielectric material & 10 Mil RT Duroid 5880 \\
\hline Patch Element size & $2.48 \mathrm{~mm} \times 2.48 \mathrm{~mm}$ \\
\hline Inter-element Spacing & $6.5 \mathrm{~mm}$ \\
\hline Width of $143 \Omega$ Tx Line & 90 micron \\
\hline Width of $140 \Omega$ Tx Line & 230 micron \\
\hline Width of $75 \Omega$ Tx Line & 400 micron \\
\hline $8 \times 32$ Array Antenna Size & $212 \mathrm{~mm} \times 56 \mathrm{~mm}$ \\
\hline
\end{tabular}

\section{Fabrication and measurement}

The antenna has been printed on 10 mils Rogger's RT Duroid material. A metallic enclosure has been developed to support and hold the antenna array. The dielectric sheet is flexible, hence a metallic adhesive (epoxy) was used to paste the antenna over the metallic plate. The input of the antenna is a coaxial connector with $2.9 \mathrm{~mm}$ jack, 2 hole flange, and Radial's Ka-Band glass bid (R280.760.040). The size of the realized antenna is $210 \mathrm{~mm}$ (length), $56 \mathrm{~mm}$ (width) and 4 $\mathrm{mm}$ thickness. The photograph of the developed antenna is shown in Figure 8.

VSWR measurement of developed antenna has been carried out using calibrated Agilent PNA microwave network analyzer N5224A. The Comparison of simulated and measured VSWR is shown in Figure 9.

The measured VSWR of the antenna is better than 1.75 over the frequency band from $34.5 \mathrm{GHz}$ to $35.5 \mathrm{GHz}$. The radiation properties of the developed antenna were measured at a compact antenna test range facility. The photograph of antenna during the measurement is shown in Figure10.

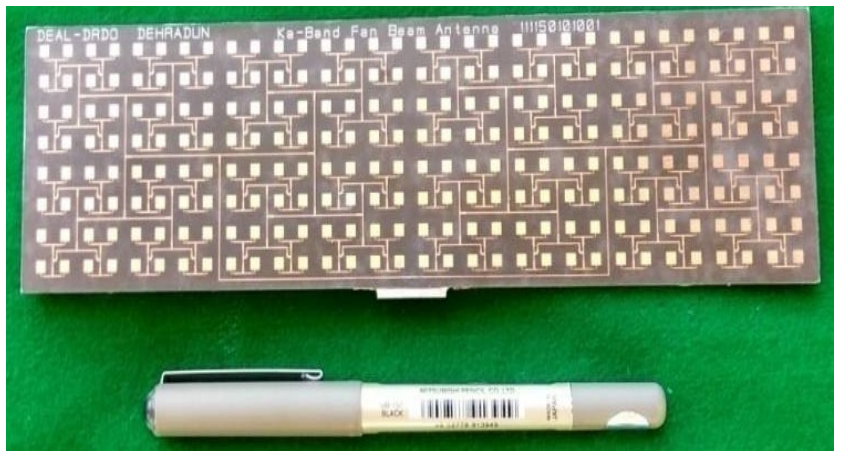

Fig.8. The fabricated 8x32 Patch array antenna.

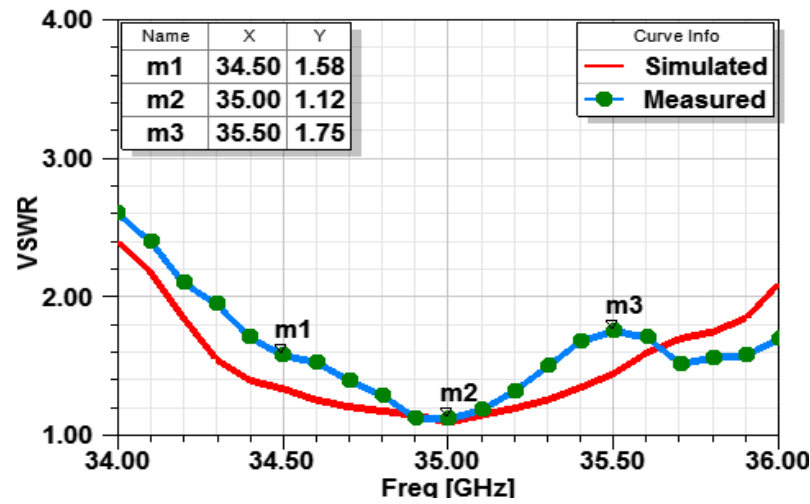

Fig.9. VSWR plot of antenna 


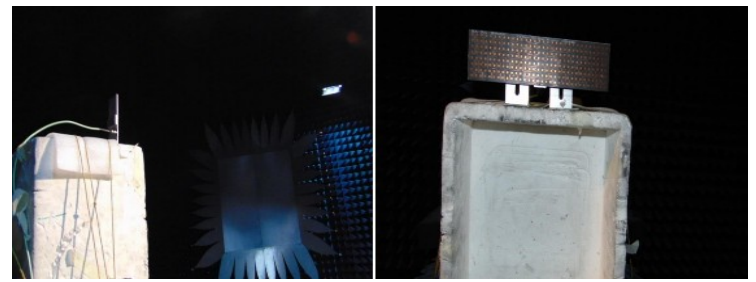

Fig.10. Measurement of antenna in CATR.

The measured radiation patterns of the antenna at different frequencies are shown in Figure 11. The gain of antenna has been estimated by gain comparison method, in which after measurement of E-plane and H-plane pattern of the antenna, the only antenna under test is replaced by standard gain horn (SGH) antenna to compare its peak value. The measured gain of the antenna is better than $25.4 \mathrm{dBi}$ over the frequency band of 34.5 to $35.5 \mathrm{GHz}$. The measured antenna gain is $1.39 \mathrm{~dB}$ lesser than the simulated value which may be accorded to fabrication tolerance and measurement inaccuracy. Measured parameters of the antenna at different frequencies are shown in Table 4.

Table 4: Measured Parameters of 8x32 Array Antenna

\begin{tabular}{|c|c|c|c|c|}
\hline \multirow{2}{*}{$\begin{array}{l}\text { Frequency } \\
(\mathrm{GHz})\end{array}$} & \multirow{2}{*}{$\begin{array}{l}\text { Gain } \\
(\mathrm{dBi})\end{array}$} & \multicolumn{2}{|c|}{ HPBW(deg) } & \multirow{2}{*}{$\begin{array}{l}\text { SLL } \\
\text { (dB) }\end{array}$} \\
\hline & & E-plane & H-plane & \\
\hline 34.5 & 25.4 & 8.6 & 2.4 & 11.3 \\
\hline 35.0 & 26.5 & 8.2 & 2.2 & 11.4 \\
\hline 35.5 & 25.7 & 8.4 & 2.3 & 12.1 \\
\hline
\end{tabular}

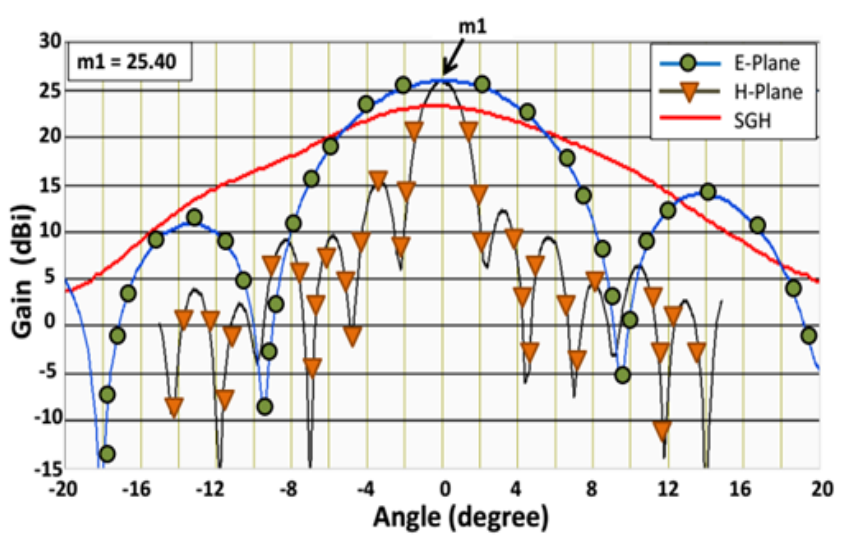

(a)

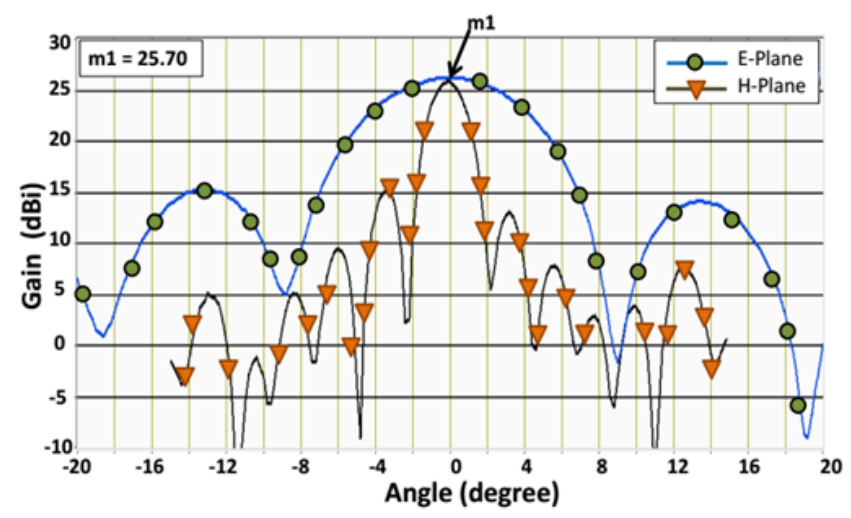

(b)

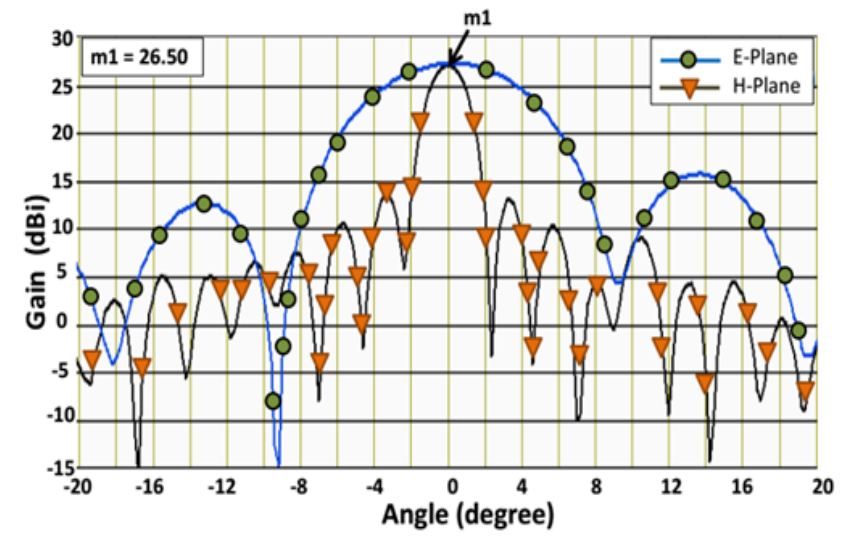

Fig.11. Measured radiation pattern of antenna (a) $34.5 \mathrm{GHz}$ (b) 35 $\mathrm{GHz}$ (c) $35.5 \mathrm{GHz}$

\section{Conclusion}

A low profile, lightweight, $8 \times 32$ microstrip patch array antenna with corporate feed network has been realized at Kaband frequency for all weather MM wave fencing system with dual radiator topology. Radiating array shows VSWR less than 2 over the frequency band 34.3 to $36 \mathrm{GHz}$. The measured gain of the antenna is $26.5 \mathrm{dBi}$, E-plane \& H-plane beamwidths are 8.4 degrees and 2.2 degrees respectively at $35 \mathrm{GHz}$. Measured results show a very good resemblance with simulated values. The antenna is most suitable for dual radiator based mm-wave RF fencing systems as an integrated security system.

\section{Acknowledgements}

The authors express their sincere gratitude and thank Director DEAL for giving permission to publish this paper.

\section{References}

[1] A.S. Barry and J. Czechanski, Ground surveillance radar for perimeter intrusion detection", in Proceeding of 19th Digital Avionics Systems Conference, October 2000, Philadelphia, USA. DOI: 10.1109/DASC.2000.884927

[2] Sumitro Ghatak, Sagar Bose, and Siuli Roy, Intelligent Wall Mounted Wireless Fencing System using Wireless SensorActuator Network, International Conference on Computer Communication and Informatics (ICCCI -2014), Jan. 03 - 05, 2014, Coimbatore, INDIA.

[3] P. Hosmer, Use of Laser Scanning Technology for Perimeter Protection, IEEE Aerospace and Electronic Systems Magazine, vol. 19, pp. 13-17, 2004.

[4] S. Hennin, G. Germana and L. Garcia, Integrated Perimeter Security System, in Proceeding of IEEE Conference on Technologies for Homeland Security, pp. 70-75, 2007.

[5] G. Pestana, LocON: A location-based services platform to improve airport safety, in Proceeding of IEEE Aerospace Conference, pp. 1-10, 2011.

[6] A. Davis and H. Chang, Airport Protection Using Wireless Sensor Networks, Proceeding of IEEE Conference on Technologies for Homeland Security, Apr. 2013.

[7] T. S. Rappaport, Y. Qiao and J. I. Tamir, J. N. Murdock, and E. Ben-Dor, Cellular broadband millimeter wave propagation and angle of arrival for adaptive beam steering systems (invited paper), in Proceeding of IEEE Radio Wireless Symposium, pp. 151-154, Jan. 2012.

[8] Muhammad S. R. and Hooshang Ghafouri-Shiraz, Evaluation of gain enhancement in improved size microstrip antenna arrays for millimeter-wave applications, International Journal 
of Electronics and Communications, vol. 81, pp. 105-113, November 2017.

[9] R. Kumar, P. K. Verma, and M.Singh, A High Gain \& Low Side Lobe Level Pillbox based Fan Beam Antenna at KaBand, Proceeding of APSYM 2014, CUSAT, Kochi.

[10] Ayman Ayd R. Saad, and Hesham A. Mohamed, Printed Millimeter-Wave MIMO-Based Slot Antenna Arrays for 5G Networks, International Journal of Electronics and Communications, vol. 99, pp. 59-69, February 2019.

[11] Nadeem A., Osama M. H., Mohamed M. M. Ali, Mohamed A. A., Saleh A. and Saleh A., Optimized broadband and dualband printed slot antennas for future millimeter-wave mobile communication, International Journal of Electronics and Communications, vol. 70, Issue 3, pp. 257-264, March 2016.

[12] Y.Chen, R.Jian, S.Ma, and S. A. Mohadeskasaeia, A Research for Millimeter Wave Patch Antenna And Array Synthesis, 26th Wireless and Optical Communication Conference (WOCC) Newark, NJ, USA, 2017.

[13] Cheng-Nan Hu, Kevin Peng, Chung-Hang Yu, Tsai-Wen Hsaio and Der-Phone Lin, Design of an mm-Wave Microstrip Antenna Array, Int. Workshop on Electromagnetics Applications (IWEM) 2015.

[14] Amin Rida, Manos Tentzeris and Symeon Nikolaou, Design of low-cost microstrip antenna arrays for mm-Wave applications, IEEE International Symposium on Antennas and Propagation (APSURSI) Spokane, WA, USA, 2011.

[15] irish Kumar and K. P. Ray, Broadband Microstrip Antenna, Artech House Inc, 2003, Norwood MA

\section{Biography of the authors}

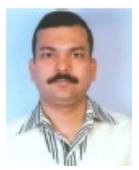

Pramendra Kumar Verma received his B. Tech. degree in Electronics Engineering from VBSPU, Jaunpur and M.E. degree in Microwave Engineering from GEC, Jabalpur. He has published more than thirty papers in International journals and IEEE conferences. His area of research includes design and development of microwave and mmwave antennas, slotted waveguide omnidirectional antenna, conformal phased array antenna, reflector antenna, waveguide components etc. He is the recipient of the DRDO Technology Award, Laboratory Scientist of the Year Award and Group Technology Award. He is a Life Fellow of ATMS society and a Life Member of IETE. He is also a reviewer of International Journals IJMWT (EuMA), MOTL, USA \& IJAMT, India

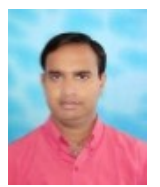

Raj Kumar obtained his M. E. degree in Microwave \& Radar from the University of Roorkee (presently IIT Roorkee). He has published more than thirty papers in international journals and IEEE conferences. His areas of interest include microwave and mm-wave antennas design including omni directional antenna, fan beam antenna, slotted array antenna, antenna for radiometry, microstrip antennas, design of waveguide filters, reflector antennas, horn antennas, conformal antennas, phased array antenna etc. He has been awarded DRDO Technology Award, Group Technology award, \& Laboratory Scientist of the Year award. He is a fellow of ATMS Society.

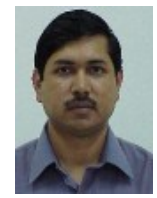

Vinod Kumar Singh Born in 1971 at Village Chanderu, District Bulandshar, Utter Pradesh, India. Post Graduated in Communication \& Radar Engineering from Indian Institute of Technology, Delhi, working as Scientist in Defence R\&D Organization, Govt. of India since 1995. Holding two patents in the area of Wideband Circularly Polarized Microstrip Antennas in $\mathrm{S}$ and $\mathrm{C}$ Bands. Published more than 30 technical papers in National and International conferences and journals. Delivered technical lectures at various occasions including National Technology and Science Days. Recipient of more than 15 National and DRDO level awards including Indian National Academy of Engineering award in 2003, NCC award in 2004, DRDO Agni Award for Excellence in Self Reliance in 2009,2010,2011 \& 2018; DRDO Performance Excellence Award in 2017 and DRDO Technology Group Award in 2008,2014,2016,2017 \& 2018. Area of interest includes Printed, Conformal, MEMS, Large MIMO, Compact Monopole and Dipole antennas for Ground and Airborne Communication systems.

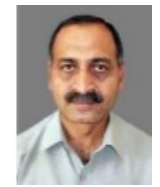

Ashok Kumar received the Ph.D. from Grapic Era University in 2020 and M.Tech. in Radar \& Communicaton form IIT Delhi in 1985. He is Associate Director of DEAL. His area of research includes design and development of RF systems, millimeter wave imaging sensors, Satcom system, IFF System, Blue green Laser, Tropo communication systems etc. $\mathrm{He}$ is a member of IEEE \& IETE. He has been awarded with DRDO Scientist of the year, DRDO Technology award, IGMDP award and Commendation Medal from SA to RM. 